\title{
Technical Note: Impact of Using Plastic Vessels in Dissolution Testing
}

\author{
Sanjay S. Shetgar \\ Dr. Reddy's Laboratories Limited, Hyderabad, India
}

e-mail:sanjayshetgar@drreddys.com

T he importance of the dissolution apparatus, its calibration, and controls to be exercised during laboratory testing have been explained in several articles. One of the key elements that is sometimes overlooked is the type of dissolution vessel. Use of the correct dissolution vessel is critical in obtaining an accurate and reproducible result.

The allowable tolerances in the USP for the dimensions of the glass vessel are quite wide and lead to variations in the dimensions from manufacturer to manufacturer and sometimes even from lot to lot.

The use of high-quality glass vessels is highly recommended. Plastic vessels, which are normally made of styrene acrylonitrile, can be used in place of glass, where appropriate. The plastic must not interfere with the analysis by sorbing, leaching, or reacting with the analyte. Many manufacturers prefer plastic vessels to glass for several reasons:

a) Plastic vessels are molded rather than hand-formed, thus the variability in dimensions is low and reproducible from vessel to vessel. It also helps to minimize errors in setting the paddle or basket height and centering.

b) Ease of handling and usage.

c) Low cost.

d) Safety.

However, the plastic vessel also has disadvantages:

a) Poor thermal conductivity, which leads to extended time to achieve a uniform temperature. At times, it may be necessary to set the bath temperature slightly higher than the analysis temperature.

b) Resistance to scratches is poor and may require more frequent replacement. Scratches could lead to particles sticking in the grooves and could even affect the dynamics of the solution.

c) Continuous usage could cause disfigurement; hence, a routine check is essential.

d) Transparency decreases over time.

A number of studies have been carried out to evaluate the impact of usage of glass versus plastic vessels, and the results are somewhat comparable. However, plastic vessels cannot be used for all products unless there is supporting evidence. Data from one such experiment is detailed below.
The study indicates that a significant variation of about $10 \%$ is observed when vessels of two different materials are used. The purpose of this article is to alert users on the impact a vessel can have if it is not specified as part of the testing parameters.

Hence, it is essential that the impact of glass or plastic vessels be assessed as part of method development. Recovery studies should be performed to ensure that the drug is not adsorbed and that it does not release interfering substances into the dissolution medium. The dissolution method should clearly describe the type of vessel to be used along with the other testing parameters.

$\begin{array}{ll}\text { EXPERIMENTAL DETAILS } & \\ \begin{array}{l}\text { Apparatus: } \\ \text { Sinker: }\end{array} & \text { USP Apparatus 1 (Basket) } \\ \text { RPM: } & 100 \mathrm{rpm} \\ \text { Time: } & 30 \mathrm{~min} \\ \text { Medium: } & 20 \mathrm{~g} \text { sodium chloride dissolved } \\ & \text { in } 10 \mathrm{~L} \text { of } 0.1 \mathrm{~N} \mathrm{HCl}, \mathrm{pH} \\ & \text { adjusted to } 1.2 \mathrm{with} 0.1 \mathrm{~N} \mathrm{HCl} \\ & \text { or } 0.1 \mathrm{M} \mathrm{NaOH} \text { (deaerated) } \\ & 900 \mathrm{~mL} \\ \text { Volume: } & 37 \pm 0.5^{\circ} \mathrm{C} \\ \text { Medium Temperature: } & \text { Experiment } 1: \text { Glass } \\ \text { Vessel: } & \text { Experiment 2: Plastic }\end{array}$

Results

\begin{tabular}{|l|c|c|}
\hline Unit & $\begin{array}{c}\text { Percent Drug Dissolved } \\
\text { Using Glass Vessels } \\
\text { Experiment 1 }\end{array}$ & $\begin{array}{c}\text { Percent Drug Dissolved } \\
\text { Using Plastic Vessels } \\
\text { Experiment 2 }\end{array}$ \\
\hline 1 & 99 & 88 \\
\hline 2 & 98 & 88 \\
\hline 3 & 99 & 92 \\
\hline 4 & 100 & 90 \\
\hline 5 & 99 & 91 \\
\hline 6 & 97 & 88 \\
\hline AVG & 99 & 90 \\
\hline
\end{tabular}

